\title{
Application of a compositional rotatable plan in modeling the propylene content in a vinyl chloride/propylene copolymer
}

\section{Marzena Wiener $^{1}$ (D) Andrzej Gawdzik ${ }^{1}$}

Received: 15 August 2019 / Revised: 19 October 2019 / Accepted: 28 October 2019 /

Published online: 2 November 2019

(c) The Author(s) 2019

\begin{abstract}
Using a fractional rotatable plan, the effect of five input parameters of the conduct of the copolymerization process on the amount of propylene built into the copolymer, obtained as a result of free radical suspension copolymerization of vinyl chloride with propylene in a batch suspension polymerization reactor, was analyzed. Using the results obtained, the analysis of variance was carried out and the influence of particular factors and their interactions on the product properties was determined. Thus, it was determined that the greatest influence on the amount of the incorporated propylene in the copolymer is exerted by the amount of propylene introduced into the system, while the effect of the initiator on the product properties analyzed was found to be negligible. A mathematical model was also made, and then it was improved through the use of stepwise regression and verification with the results of laboratory experiments. The adequacy of the achieved model was confirmed using the Fisher-Snedecor test. It was obtained the conformity of the constructed model with the analysis of the influence of particular factors on the propylene content in the copolymer.
\end{abstract}

\section{Introduction}

The polymerization of vinyl chloride in suspension results in a high purity product and is one of the most frequently used methods of polymer production. It is carried out in autoclaves lined with clad steel or acid resistant steel and equipped with a propeller stirrer and a heating and cooling shell. The polymerization process is carried out in an aqueous medium, which allows maintaining a strictly defined temperature. Too high a temperature can lead to the abstraction of hydrogen chloride and the transfer of the kinetic chain to the polymer. In an aqueous

Marzena Wiener

mwiener@uni.opole.pl

1 Institute of Technical Sciences, University of Opole, Dmowskiego 7-9, 46-365 Opole, Poland 
medium, a water insoluble monomer and suspension stabilizer are dispersed. Polyvinyl alcohol, methyl cellulose and gelatin are used as stabilizers. Modifiers of polymer properties, $\mathrm{pH}$ regulators and initiators are also introduced into the aqueous phase. The polymerization time, morphology and properties of the product are influenced by the type and number of initiators used. Organic peroxides and nitrogen compounds are most often used as initiators in suspension polymerization. Depending on the type of polymer obtained, the maximum polymerization pressure may range from 0.5 to $1.4 \mathrm{MPa}$, while the polymerization temperature usually remains within the range of $52-63{ }^{\circ} \mathrm{C}$. The completion of the polymerization process is determined by the achievement of the assumed pressure drop to the level of about $0.35-0.2 \mathrm{MPa}$. After degassing of the unreacted vinyl chloride, the polymer suspension is centrifuged and then, because the product still contains about $20 \%$ water, the polymer is subjected to a two-stage drying process [1-3].

Copolymers of vinyl chloride with propylene usually contain $2-10 \%$ of propylene monomer. They are characterized by increased impact strength, lower hardness, higher elongation at break, high melt flow rate and better thermal stability in relation to polyvinyl chloride. Due to their lower polarity, they show much better processing and utility properties. Chlorine atoms are statistically distributed in the chains, which makes them highly flexible, less packed and therefore less crystalline. At low propylene content, the copolymers are well soluble in organic solvents $[2,3]$. The development of research on copolymers of vinyl chloride and propylene dates back to the 1960s and 1970s.

Kozłowski and Łaskawski [4] examined the mechanical, thermal, rheological and physicochemical properties of copolymers of vinyl chloride and propylene with different amounts of comonomer. The obtained results were compared in the properties of polyvinyl chloride and a copolymer of vinyl chloride with vinyl acetate. They showed improvement of properties of the studied copolymers with olefins in relation to vinyl chloride homopolymer.

The homopolymer and copolymer of vinyl chloride pass through identical intermediate states of hydrogen chloride separation in which alkyl, allyl and polyene radicals are observed. Albarino et al. [5] examined the mechanism of separation of hydrogen chloride for polyvinyl chloride and three copolymers of vinyl chloride with propylene at different propylene contents. They showed that propylene disperses along the copolymer chain in a random manner and effectively blocks hydrochlorination by terminating the growth of polyene sections and thus the formation of short sequences.

Another important property of copolymers as thermoplastic material is their thermal stability. Thermogravimetric analysis showed [6] that thermal stability of a copolymer of vinyl chloride with propylene is much better than that of other copolymers of vinyl chloride, e.g., with ethylene, vinyl acetate or vinylidene chloride. The copolymer also shows improved thermal stability compared to polyvinyl chloride. It depends less on the molecular weight, but the concentration of propylene groups in the polymer chain has a big influence on it.

Propylene, even at low concentrations, has a significant influence on the kinetics and mechanism of the copolymerization process. In the copolymer, it acts as a 
chain-bearing compound, which results in lower molecular weight and copolymerization rate than in the case of polyvinyl chloride [7].

The molecular weight of a copolymer of vinyl chloride with propylene is lower than the molecular weight of polyvinyl chloride, thus limiting the area of application of the copolymer. Adding small quantities of monomers with two or more active double bonds can increase the molecular weight of the copolymer without causing crosslinking. When increasing the molecular weight, diallyl and triallyl esters are the most effective [8].

Chan and Worman [9] stated that also the density of the copolymer determined by spectroscopic method is related to the content of propylene. They determined that the lowest value of density being obtained for the highest molar percentage of propylene. These results were confirmed by Ravey [10], who determined the density of the copolymer based on chlorine analysis.

Apart from physicochemical properties, rheological properties of the copolymer are also important. It was shown that the melt flow rate and specific viscosity are related to the amount of propylene in the copolymer [11]. An increase in propylene content results in lower specific viscosity values and an increase in the flow of the copolymer, which leads to a product with better processing characteristics.

The porosity of beads obtained in suspension copolymerization is an important property in the processing of copolymers. Langsam and Mango [12] and Mango [13] studied suspension copolymerization of vinyl chloride with propylene in which the copolymer was produced in the presence of a binary stabilization system. Hydroxypropyl methylcellulose was a primary stabilizer, while polyvinyl alcohol with a low degree of hydrolysis was a secondary stabilizer. They showed that the addition of an additional stabilizer increased the porosity of the beads without any significant change in the molecular weight of the copolymer.

Copolymers of vinyl chloride with propylene can also be used in the form of their blends with polyvinyl chloride ( $\mathrm{PVC} /(\mathrm{CV} / \mathrm{P}))$ [14-16]. It is a form of modification of vinyl chloride homopolymer in order to improve its properties and processing characteristics.

The aim of this paper is to determine the effect of five working parameters on the content of propylene in a copolymer of vinyl chloride with propylene by developing a mathematical model characterizing the analyzed process. The aim was achieved using statistical methods of planning experiments, the method of least squares and stepwise regression. These methods are widely used in polymer studies. It is a set of statistical and mathematical techniques based on the matching of empirical models with experimental data which must describe the behavior of the data set in order to produce statistical forecasts [15].

Optimization of the process with the use of a fractional rotatable plan was carried out by, among others, Gadomska-Gajadhur et al. [17] in the ring-opening polymerization of lactide process using a biocompatible catalyst, Vieira and Lona [18] in the process of atom-transfer radical polymerization (ATRP), as well as Mah et al. [19] in the preparation of TFC membranes with the highest xylose separation factor. Colonna et al. [20], on the other hand, analyzed the effect of different processing parameters during the production of poly(butylene terephthalate) nanocomposites, using the total factorial experiment for the three input parameters. Statistical methods 
were also used by Chabbi et al. [21, 22] in his research during the turning process of polyoxymethylene polymer (POM C).

In connection with the above, statistical techniques are used in designing experiments, developing mathematical models, estimating the impact of individual factors, and their aim is to find the best conditions for conducting the process under consideration. As a result, the properties of the obtained product are improved in a shorter time and at a much lower cost than in the case of using experimental methods [23-25].

\section{Experimental methods}

\section{Copolymerization of vinyl chloride with propylene}

Laboratory experiments on the copolymerization of vinyl chloride with propylene were carried out in a periodic tank laboratory reactor equipped with a stirrer and a heating and cooling shell. The research cycle began with the loading of all raw materials into the reactor in a strictly defined order.

The preparation of the components consisted in purification of vinyl chloride and propylene, demineralization of water with ionites, dissolution of the initiator (lauroyl peroxide) in a monomer and emulsifier (suspension stabilizer-methylcellulose) in water.

A 51 autoclave, made of stainless steel and equipped with a propeller stirrer and a heating and cooling jacket, was filled with a specific amount of demineralized water, a solution of the stabilizer in water (a protective colloid) and a solution of the initiator in a monomer. The reactor was then blown out with nitrogen, and liquid vinyl chloride and liquid propylene were introduced by mixing. The polymerizer was filled to the volume of 0.8-0.9. After loading the components, hot water was introduced into the reactor shell in order to heat the reaction mixture to the assumed temperature. In order to obtain a copolymer with the desired properties, it was necessary to maintain a specific temperature. The copolymerization time at a temperature of 37.5-67.5 ${ }^{\circ} \mathrm{C}$ and under a pressure of $0.49-1.37 \mathrm{MPa}$ was from 12 to $15 \mathrm{~h}$. The end of the process was determined by the pressure drop in the reactor to $0.20-0.35 \mathrm{MPa}$.

\section{Experimental design methodology}

The process of copolymerization of vinyl chloride with propylene was carried out using the method of experiment design. The half-fractional composition rotatable design was applied, in which the input parameters were changed on five levels.

Thanks to the use of a rotatable design, the information contained in the designated regression equation will be evenly distributed on a hypersphere of a certain radius. This design also ensures uniform variance while drawing away from the design's center, as well as the achievement of a minimum of systematic errors, which are related to the lack of adequacy of presenting research results in the form of second-level polynomials [26]. 
The influence of five working parameters on the quality of the final product was analyzed. For each of these parameters, the range of its variability was determined. These parameters, being independent variables (explanatory variables) in the analysis, were marked with letters $a, b, c, d$ and $e$. For each selected set of values of these five working parameters, the product obtained was analyzed for the amount of propylene incorporated in the copolymer.

The methodology of rotational stability plans required the initial coding of input factors that simplifies and unifies the experiment's design. Input parameters have been encoded on five levels: basic, higher, lower, star higher and star lower. The original value at the basic level (assumed after encoding as equal to 0 ) is the arithmetic mean of the values limiting the ranges of variability of the considered parameters (with values equal to -1 and 1 , respectively, after encoding).

The obtained copolymer was tested for the previously defined response function, i.e., propylene content in the copolymer. The original and coded values of each variable at all levels and the output values are shown in Table 1.

The total number of experiments $(N)$ was assumed according to Eq. 1, and their number was limited by using the so-called fractional repetition [26, 27]:

$$
N=n_{k}+n_{\alpha}+n_{0}=2^{k-m}+2 k+n_{0}
$$

where $N$ number of experiences, $n_{k}$ number of two-level plan measurements, $n_{\alpha}$ number of measurements at star points, $n_{0}$ number of measurements in the middle of the plan, $k$ total number of factors, $m$ fractionality of the plan.

The advantage of $2^{k-m}$ plans is that each regression coefficient is determined independently based on all $N$ experiences. They also have the smallest determinant of the covarian matrix; therefore, all coefficients are calculated with the same and minimum variance [28].

On the basis of the obtained values of the response function, the verification of statistical hypotheses was used for further research. In this paper, all calculations included in the work were made using Statistica 12 program of StatSoft Polska.

\section{Analysis of variance}

The analysis of variance (ANOVA) was carried out in order to estimate the effect of the selected input factor on the resulting factor. The effects of the five main factors and their first-order interactions on the process were studied. The aim was to determine which factors and to what extent have a significant impact on the response function. The application of the experimental design allowed to determine the impact strength of discontinuous variables by quantifying the effects of the main factors and effects of interactions, determined with less error than in the case of studies without an experimental design [28, 29].

A Fisher-Snedecor statistical test was used to estimate the significance of the influence of input parameters on the effect of the copolymerization process. In the analysis of variance, the mean squares of deviations $(M S)$ were compared with the mean square error and a test statistic $F$ is obtained, which allows determining whether the influence of a given factor or interaction of factors is statistically 


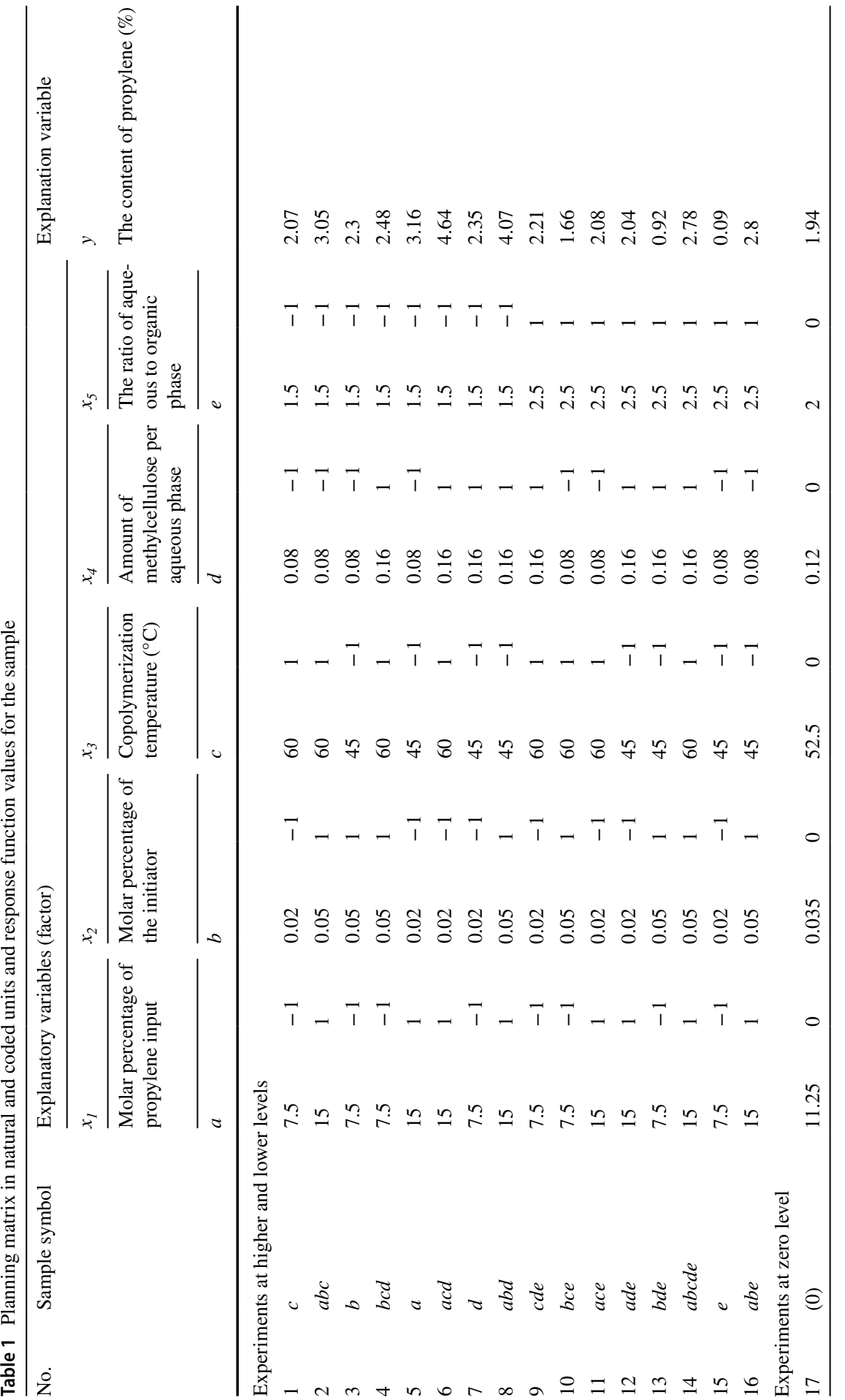




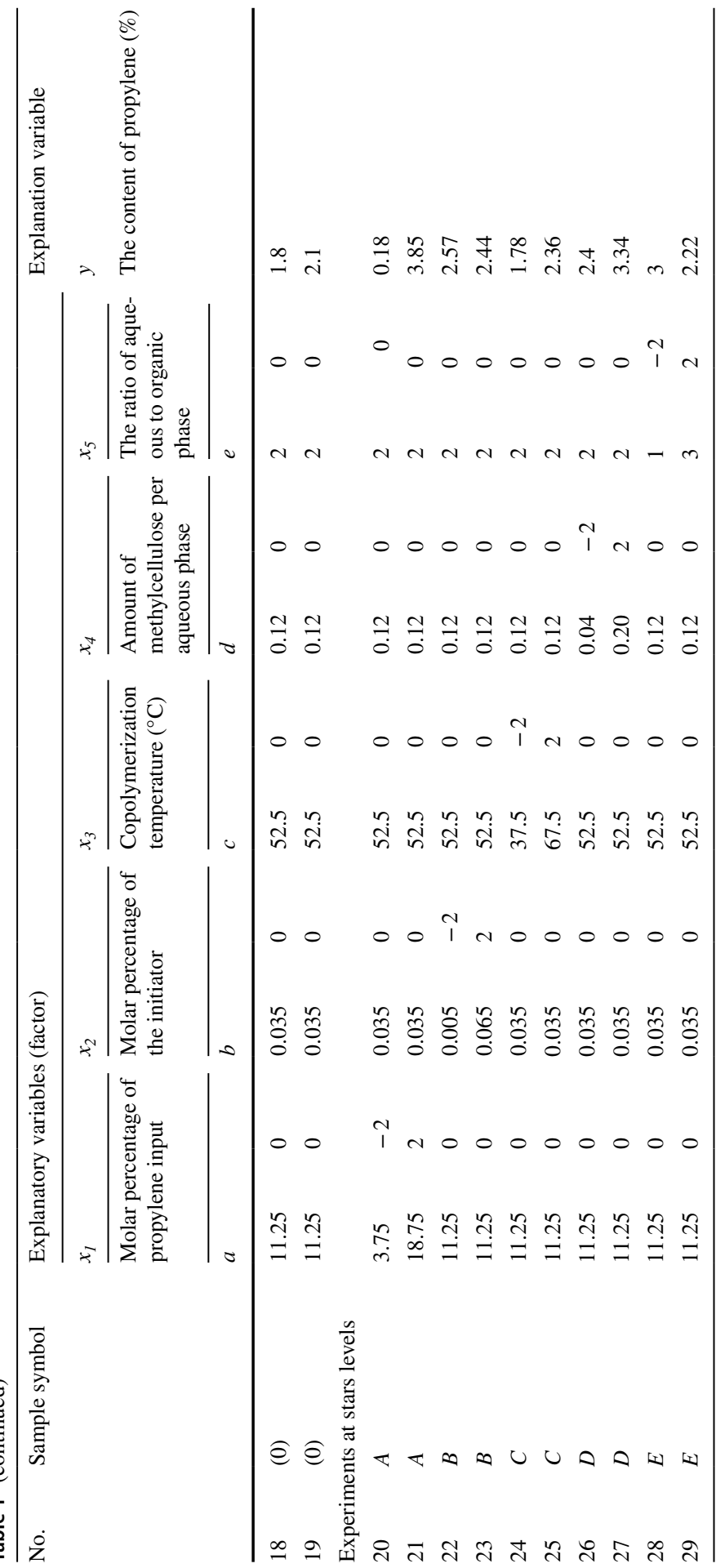


significant or accidental [30]. The assessment of significance was performed by assessing the significance of the appropriate variance from the sample in comparison with the variance of repeatability. The variability of the experiment error was calculated using the estimation of variability in design layouts repeated at the zero level. Measurements in repeated systems were made under the same conditions, with identical input values; therefore, the error variability so determined represented the error origination only in the uncertainty of measurement of the output quantity.

\section{Mathematical modelling}

The mechanism of the process of copolymerization of vinyl chloride with propylene is a complex process, and it is practically impossible to obtain a system of differential equations describing the investigated system. In this situation, in order to comprehensively examine the course of the process and obtain the necessary information, it was most appropriate to describe the relationship between the response functions and the examined parameters on the basis of statistical methods of design of experiments.

In studies of objects characterized by many input factors, the most common form of a model that approximates nonlinear objects is an algebraic linear-square polynomial, containing double interactions, closely related to the type of experimental plan used. Equation 2 describes the course of a given phenomenon.

$$
y=b_{0}+\sum_{i=1}^{5} b_{i} x_{i}+\sum_{\substack{j, i=1 \\ j \neq 1}}^{5} b_{j i} x_{j} x_{i}+\sum_{i=1}^{5} b_{i i} x_{i}^{2}
$$

where $b_{0}$ free expression, $b_{i}$ linear expressions, $b_{j i}$ square expressions, $b_{i i}$ expressions of double impact.

Independent variables selected for the model may or may not have a significant impact; therefore, it is possible to reduce the number of regression coefficients only to those statistically significant. The fact that an initially coefficient does not show a significant impact on a variable does not mean that there is no such impact. The absence of statistical significance does not mean that, after omitting the other coefficients, this parameter will still not affect the response variable, as the explanatory function of the variable standing by parameter $b$ can be performed by the other variables.

For the selection of variables in the mathematical model, the so-called sequential procedure, also known as the retrograde step-by-step approach, was used. Efroymson's step-by-step regression procedure [31] has proved its usefulness in practice, because although there are many methods to carry out regression, the selection of variables was done using the above-mentioned method. The decision on the shape of the model was made on the basis of test $F$-statistic. Removal of the variable slightly decreased the determination coefficient $R^{2}$, whereas significantly reduces the mean square of deviations from the model [32-38]. 
In order to determine which part of the total variability of the response variable was explained by the regression model, the determination coefficient was calculated $\left(R^{2}\right)$. To generalize the modelling results for the whole set, the corrected value shall be determined $R^{2}$ [30]. Its value indicates the level of fitting of the regression equation to another sample from the same set. The adequacy of the determined regression equation was checked with the help of the test statistic $F$-Snedecor at the confidence level of $95 \%$.

The obtained empirical regression function is an approximation of regression in the whole population. A related problem is the assessment of the discrepancy between the measured values of the dependent variable and the values estimated with the use of the model [39, 40]. The information about the average value of empirical value deviation of the variable depending on the values calculated on the basis of the mathematical model was obtained by estimating the standard error of estimation.

\section{Results and discussion}

The results of the analysis of variance and the significance of the effects on the amount of propylene incorporated in the copolymer are presented in Table 2. Relevance has been checked at the level of $\alpha=0.05$. The critical value of the Fisher test for a given materiality level is equal to $F_{(0.05 ; 1 ; 2)}=18.51$.

Significant influence of the main effects was demonstrated for factors $a, c, d$ and $e$ as well as for the effects of cooperation of factors $b c$ and $b d$. Factors $a$ and $e$ have the greatest influence. The average value of the linear effect of factor $a$ is 1.317 , and it is the highest in the table of variational analysis, which can be seen not only in the table, but also in the Pareto chart presented in Fig. 1. This means that with an increase in the amount of propylene from 7.5 to $15 \%$ mole. The amount of propylene incorporated in the copolymer will increase on average by $1.317 \%$. On the other hand, when the ratio of aqueous to organic phase is increased from 1.5 to 2.5 , the

Table 2 Analysis of variance and the evaluation of main effects and their interactions ( $a$-molar percentage of propylene input, $b$ - the molar percentage of the initiator, $c$-copolymerization temperature, $d$ amount of methylcellulose per aqueous phase, $e$ - the ratio of aqueous to organic phase)

\begin{tabular}{lllllll}
\hline Factor & $\begin{array}{l}\text { Factor effect } \\
F E_{i}\end{array}$ & $\begin{array}{l}\text { Sum of squares } \\
S S\end{array}$ & $\begin{array}{l}\text { Degree of } \\
\text { freedom } \\
d f\end{array}$ & $\begin{array}{l}\text { Mean square } \\
M S\end{array}$ & $\begin{array}{l}F \text { test } \\
F_{(0.05 ; 1 ; 2)}\end{array}$ & $p$ value \\
\hline$a$ & 1.317 & 6.943 & 1 & 6.943 & 308.131 & 0.003230 \\
$c$ & 0.405 & 0.656 & 1 & 0.656 & 29.117 & 0.032671 \\
$d$ & 0.535 & 1.145 & 1 & 1.145 & 50.809 & 0.019119 \\
$e$ & -1.192 & 5.688 & 1 & 5.688 & 252.436 & 0.003938 \\
$b c$ & -0.435 & 0.757 & 1 & 0.757 & 33.590 & 0.028504 \\
$b d$ & -0.425 & 0.723 & 1 & 0.723 & 32.064 & 0.029801 \\
Error & & 0.045 & 2 & 0.023 & - & - \\
\hline
\end{tabular}


Level of test probability

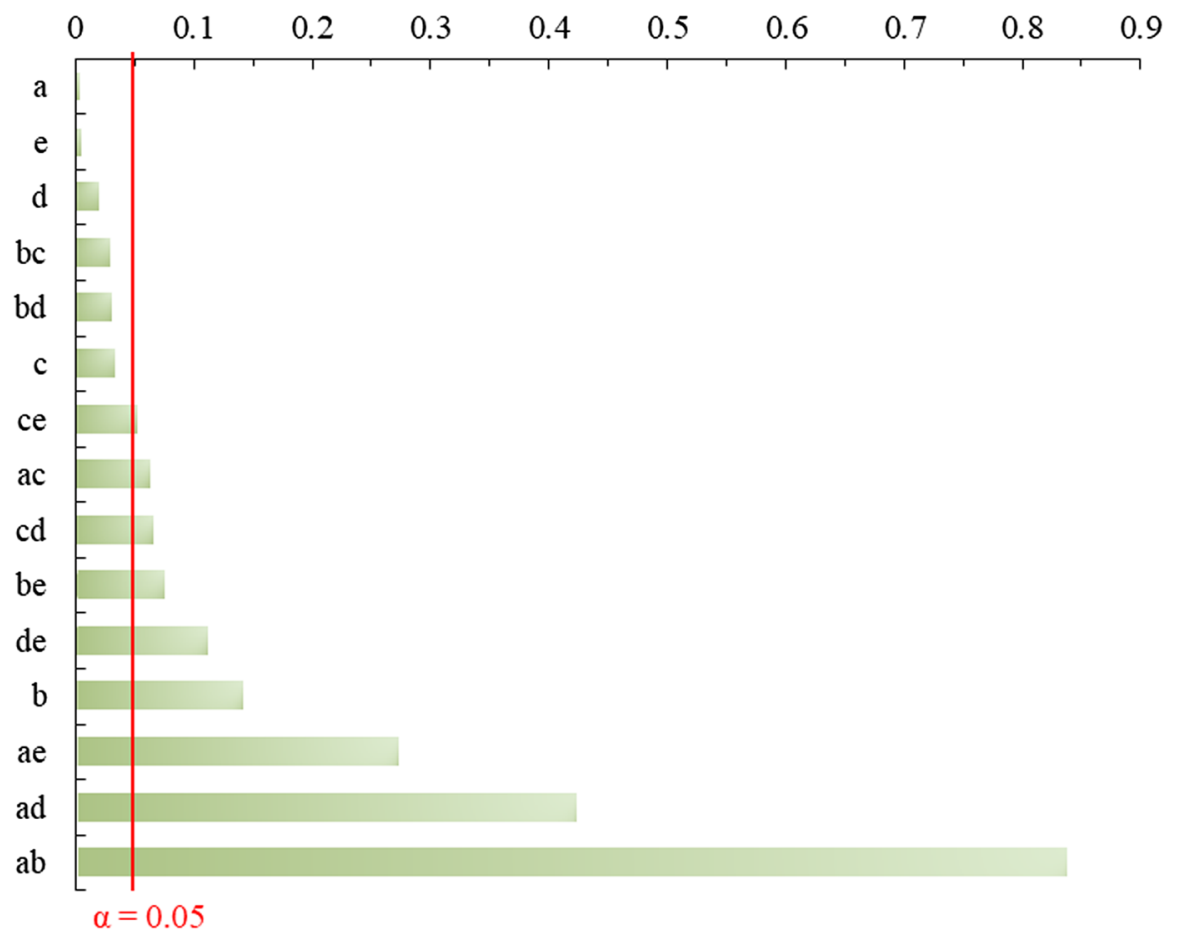

Fig. 1 Values of significance level of factors

content of propylene in the copolymer decreases on average by $1.192 \%$, as indicated by the average value of the linear effect $e$. This is due to the reduction in the amount of vinyl chloride in the mixture which, containing a double bond, in the process of copolymerization of vinyl chloride with propylene is responsible for connecting propylene to the monomer chain.

The impact of factor $b$ was also considered depending on the levels of factor $c$, and $d$ is shown in Figs. 2 and 3. In Fig. 1, it can be seen that the increase in the initiator $(b)$ alone does not have a significant effect on the propylene content of the copolymer (Fig. 1.) However, in interaction with temperature or with an increase in methylcellulose, the test statistic $F$ exceeds the critical value, and thus the interaction of $b c$ and $b d$ becomes statistically significant at a confidence level of $95 \%$.

In this paper, the mathematical model of a given function has been made as an algebraic linear-square polynomial, containing double interactions. Regression coefficients were determined using the least squares method. The relevance of the regression coefficients has been checked at the level of $\alpha=0.05$, and significant effects were bolded. Equation 3 shows the full regression equation. 
Effect of interaction of factors bc

$$
F_{(1 ; 2)}=33.590, p=0.02850
$$

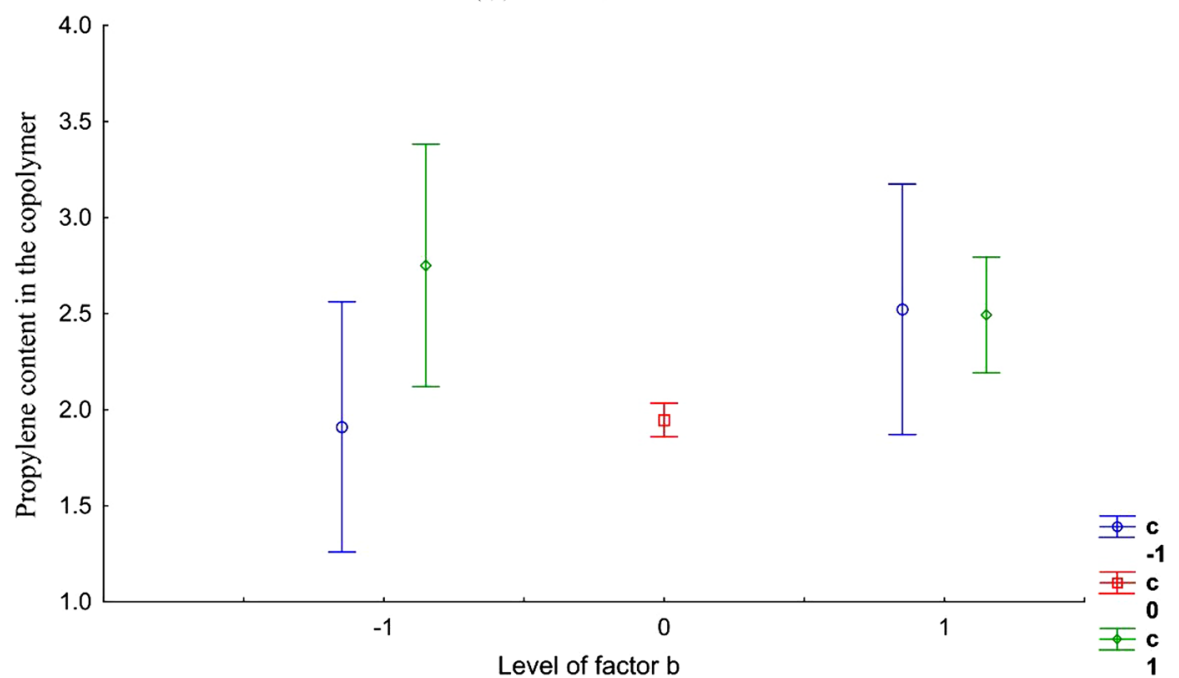

Fig. 2 Interaction of factor $b$ with factor $c$

\section{Effect of interaction of factors bd}

$$
F_{(1 ; 2)}=32.064, p=0.02980
$$

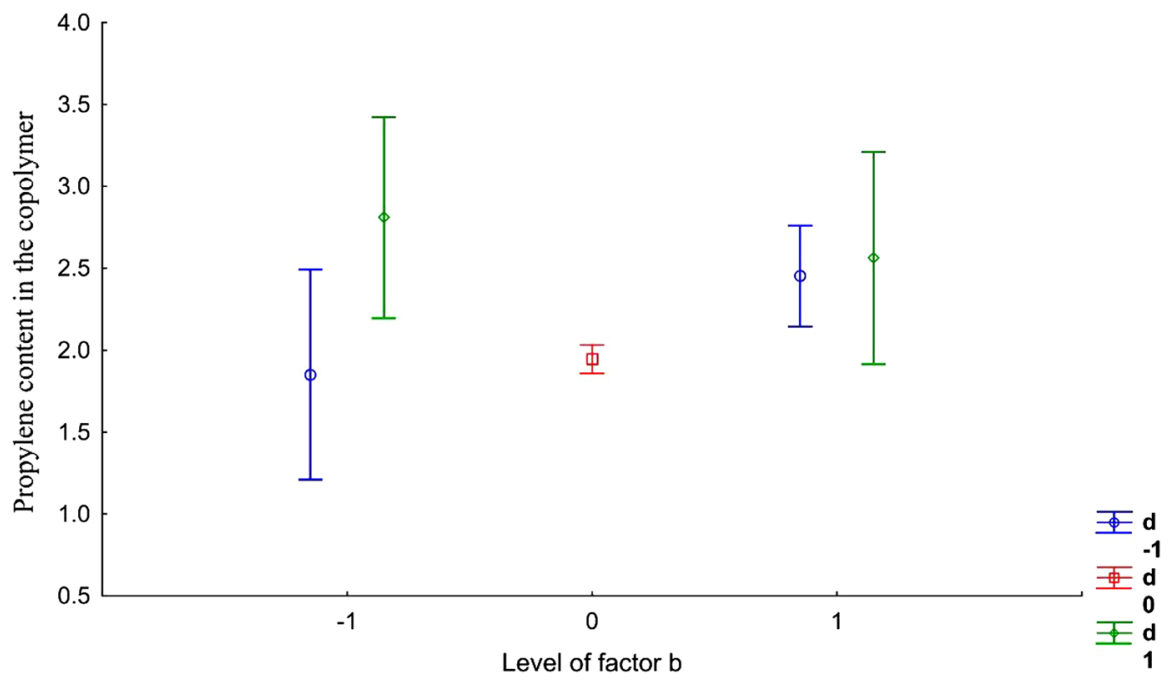

Fig. 3 Interaction of factor $b$ with factor $d$ 
Table 3 Statistically significant coefficients of stepwise regression

\begin{tabular}{lclll}
\hline Coefficient $b_{i}$ & $\begin{array}{l}\text { Value of the } \\
\text { coefficient } b_{i}\end{array}$ & $\begin{array}{l}\text { Standard } \\
\text { error of } b_{i}\end{array}$ & \multicolumn{1}{l}{$t$ test } & $p$ value \\
\hline$b_{0}$ & 1.985 & 0.124 & 15.959 & 0.00000 \\
$b_{1}$ & 0.745 & 0.069 & 10.789 & 0.00000 \\
$b_{3}$ & 0.183 & 0.069 & 2.655 & 0.01801 \\
$b_{4}$ & 0.257 & 0.069 & 3.717 & 0.00207 \\
$b_{5}$ & -0.462 & 0.069 & -6.698 & 0.00001 \\
$b_{23}$ & -0.218 & 0.085 & -2.572 & 0.02126 \\
$b_{24}$ & -0.213 & 0.085 & -2.513 & 0.02390 \\
$b_{44}$ & 0.207 & 0.065 & 3.168 & 0.00636 \\
$b_{55}$ & 0.142 & 0.065 & 2.172 & 0.04632 \\
\hline
\end{tabular}

$$
\begin{aligned}
y= & 1.986+0.745 x_{1}+0.048 x_{2}+0.183 x_{3}+0.257 x_{4} \\
& -0.463 x_{5}+0.009 x_{1} x_{2}-0.143 x_{1} x_{3}+0.038 x_{1} x_{4} \\
& -0.056 x_{1} x_{5}-0.218 x_{2} x_{3}-0.213 x_{2} x_{4}+0.129 x_{2} x_{5} \\
& +0.139 x_{3} x_{4}+0.158 x_{3} x_{5}-0.103 x_{4} x_{5}-0.007 x_{1}^{2} \\
& +0.115 x_{2}^{2}+0.006 x_{3}^{2}+0.206 x_{4}^{2}+0.141 x_{5}^{2}
\end{aligned}
$$

Table 3 present the results of the stepwise regression used for the selection of the mathematical model. Critical value of $t$ test used during the stepwise regression is $t_{(0.05 ; 15)}=2.131$.

Performing step regression allowed to include $b_{3}, b_{23}, b_{24}$ and $b_{55}$ coefficients into the mathematical model. This is reflected in the significance of the determined linear effects for the amount of the propylene incorporated in the copolymer presented in Fig. 1. While the effect of increased propylene input and reduced vinyl chloride input could have been predicted, the analysis also showed a significant effect of the input of the stabilizer into the system on the propylene content in the copolymer. Increasing the amount of methylcellulose dissolved in the aqueous phase by one

Table 4 Evaluation of the model before and after stepwise regression

\begin{tabular}{lll}
\hline Statistics & Value & \\
\cline { 2 - 3 } & $\begin{array}{l}\text { Before } \\
\text { stepwise } \\
\text { regression }\end{array}$ & $\begin{array}{l}\text { After step- } \\
\text { wise regres- } \\
\text { sion }\end{array}$ \\
\hline Correlation coefficient $R$ & 0.973 & 0.968 \\
Coefficient of determination $R^{2}$ & 0.947 & 0.936 \\
Adjusted coefficient of determination & 0.816 & 0.881 \\
$F$ test & 7.215 & 16.956 \\
$p$ value & 0.00371 & 0.00000 \\
Standard estimation error & 0.421 & 0.338 \\
\hline
\end{tabular}


unit, i.e., 0.04, results in an increase in the amount of incorporated propylene by an average of $0.257 \%$. Equation 4 presented the mathematical model after stepwise regression.

$$
\begin{aligned}
y= & 1.985+0.745 x_{1}+0.183 x_{3}+0.257 x_{4}-0.462 x_{5} \\
& -0.218 x_{2} x_{3}-0.213 x_{2} x_{4}+0.207 x_{4}^{2}+0.142 x_{5}^{2}
\end{aligned}
$$

The evaluation of the model determined by the method of least squares before and after stepwise regression is presented in Table 4. The critical value of the $F$ test for the regression equations is, respectively, equal $F_{(0.05 ; 20 ; 8)}=3.15$ and $F_{(0.05 ; 13 ; 15)}=2.448$.

In the first case, $F$-statistic, which verifies the hypothesis of the significance of the whole model, is equal to 7.215. The probability level $p$ lower than the assumed level of significance indicates the adequacy of the mathematical model. Strong correlation of the dependent variable with independent variables is indicated by the value of correlation coefficient, which is 0.973 . The model obtained explains in $95 \%$ the variability of propylene content in the copolymer, which proves its good fit; however, a high value of determination coefficient is dependent on a large number of independent variables in the model.

After applying a stepwise regression, when removing insignificant coefficients, there was no drastic decrease in correlation or determination coefficient. Both are above $93 \%$, while the adjusted determination coefficient increased by more than $6 \%$ up to $88 \%$. The value of the test $F$-statistic, and thus the probability level $p$, indicates the adequacy of the estimated mathematical model.

The correctness of the mathematical model determined was checked using eight experiments carried out at different input quantities, including two experiments carried out in the middle of the design. The values of the input quantities

\section{The experimental values relative to the theoretical}

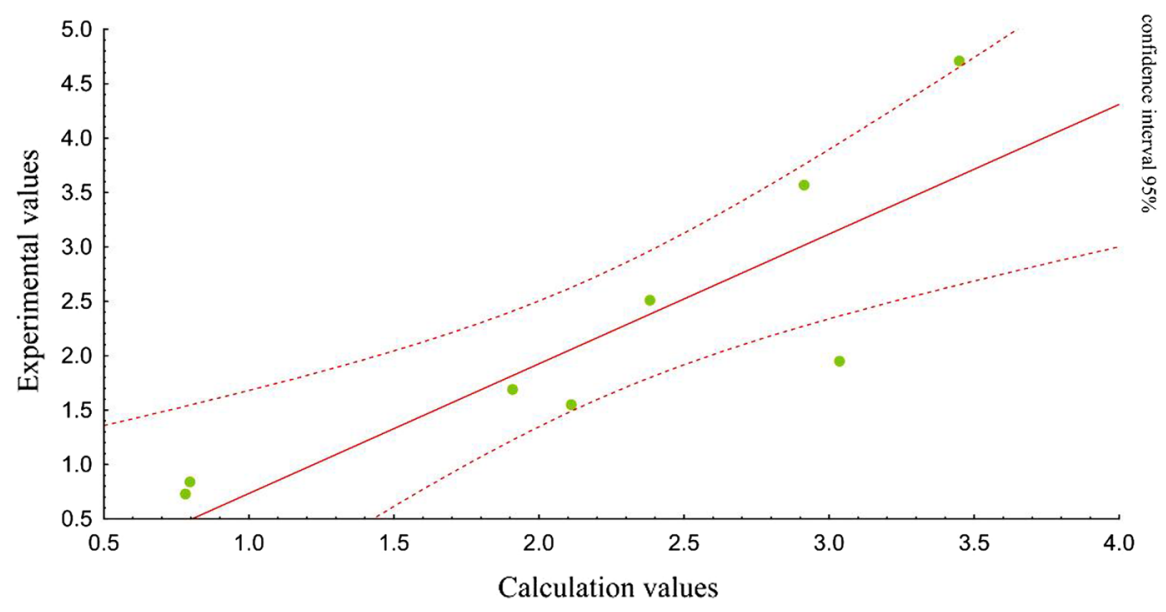

Fig. 4 Spread of experimental and computational values 
are determined by the relation used to code the values in Table 1 . The laboratory results obtained were compared with the results obtained using the mathematical model determined earlier. Figure 4 shows a diagram of the scattering of experimental values in relation to theoretical values. Deviations from this trend line are due to typical calculation rounding as well as measurement errors. In the case of the amount of propylene built into the copolymer, it can be seen that almost all the points are within the set confidence interval of $95 \%$ which indicates the adequacy of the designated mathematical model.

\section{Conclusions}

In this paper, the dependence of the amount of propylene incorporated in a copolymer of vinyl chloride with propylene on the change of five input parameters of the process was analyzed. In order to achieve this goal, a rotatable fractional experimental design was used. The values of the input quantities were changed at five levels. In the classical approach to experimental studies which determine the influence of the indicated parameters on the analyzed response functions, $5^{5}$ syntheses should be performed in total. The use of the method of planning experiments allowed reducing the number of experiments from 3125 to 29 , which significantly lowers the timeand labor consumption of conducted experiments.

Moreover, analysis of variance, analysis of main effects and interactions, least square regression and step regression were carried out. Performing these analyses made it possible to build and then verify the mathematical model of the studied process.

The study showed that the amount of propylene incorporated in the copolymer was strongly influenced not only by the amount of propylene introduced, but also by the amount of methylcellulose introduced and the ratio of the aqueous phase to the organic phase containing vinyl chloride. The values of their main effects were 1.317 and -1.192 , respectively, while the values of the main effects of the other statistically significant parameters and their interactions ranged from -0.435 to 0.535 . Obtaining such high values of these two parameters is the result of an increase in the amount of propylene reacting with double bond in vinyl chloride, as well as an increase in the ratio of aqueous phase to organic phase, thus reducing the amount of monomer in the mixture.

The use of the least squares method makes it possible to estimate the regression coefficients for individual response variables and to create initial forms of mathematical models of the copolymerization process. The regression coefficients were estimated for a linear regression model due to the linearity of the parameters, which was determined in the form of an algebraic polynomial linear-square, containing double interactions and closely related to the type of experimental design used.

The use of stepwise regression made it possible to eliminate insignificant parameters from the model, and thus to obtain its simpler form. For the model obtained, the $F$ value of 16.956 significantly exceeded the critical value of 2.448 . The evaluation of the Fisher-Snedecor test model confirmed the adequacy of the mathematical model for the analyzed dependent variable. Moreover, experimental verification of 
the model has shown that with different values of explanatory variables, the estimated model can be successfully used in the prediction of the values of explanatory variables.

Open Access This article is distributed under the terms of the Creative Commons Attribution 4.0 International License (http://creativecommons.org/licenses/by/4.0/), which permits unrestricted use, distribution, and reproduction in any medium, provided you give appropriate credit to the original author(s) and the source, provide a link to the Creative Commons license, and indicate if changes were made.

\section{References}

1. Obłój-Muzaj M (1997) Polichlorek winylu. WNT, Warszawa

2. Szlezyngier W (1998) Tworzywa sztuczne Tom 1. FOSZE, Rzeszów

3. Pielichowski J, Puszyński A (1998) Technologia tworzyw sztucznych. WNT, Warszawa

4. Kozłowski M, Łaskawski W (1980) Ocena własności kopolimerów chlorku winylu/octanu winylu (CW/OW) oraz chlorku winylu/propylenu $(\mathrm{CW} / \mathrm{P}) \mathrm{w}$ porównaniu z PCW. Chemia Stosowana 24:409-420

5. Albarino RV, Otocka EP, Luongo JP (1971) Spectroscopy of irradiated vinyl chloride-propylene copolymers. J Polym Sci A-1 Polym Chem 9:1517-1527. https://doi.org/10.1002/pol.1971.15009 0605

6. Weintraub L, Zufall J, Heiberger CA (1968) Thermogravimetric analysis of vinyl chloride-propylene copolymers and other PVC resins. Polym Eng Sci 8:64-73. https://doi.org/10.1002/pen.76008 0111

7. Ravey M, Waterman JA, Shorr LM, Kramer M (1976) Vinyl chloride-propylene copolymerization. J Polym Sci Polym Chem Ed 14:1609-1616. https://doi.org/10.1002/pol.1976.170140704

8. Waterman JA, Shorr LM, Ravey M, Kramer M (1977) Molecular weight enhancement of vinyl chloride-propylene copolymers. J Appl Polym Sci 21:1615-1619. https://doi.org/10.1002/ app.1977.070210617

9. Chan RKS, Worman CH (1974) Characterization of vinyl chloride-propylene copolymers. Polym Eng Sci 14:389-391. https://doi.org/10.1002/pen.760140515

10. Ravey M (1975) Composition-density relation for vinyl chloride-propylene copolymers. J Polym Sci Polym Chem Ed 13:2635-2637. https://doi.org/10.1002/pol.1975.170131120

11. Langsam M (1977) Properties of vinyl chloride-propylene copolymers prepared by incremental feed and batch feed procedures. J Appl Polym Sci 21:1057-1071. https://doi.org/10.1002/ app.1977.070210420

12. Langsam M, Mango PA (1986) Physical properties of vinyl chloride-propylene copolymers. J Appl Polym Sci 31:2361-2376. https://doi.org/10.1002/app.1986.070310733

13. Mango PA (1982) Vinyl chloride-propylene copolymers having increased porosity. US4464519

14. Kozłowski M, Łaskawski W (1980) Two-component blends of poly (vinyl chloride) with some vinyl chloride copolymers I. Rheological characteristics of melts. Angew Makromol Chem 91:1-15. https ://doi.org/10.1002/apmc.1980.050910101

15. Kozłowski M, Łaskawski W (1980) Two-component blends of poly (vinyl chloride) with some vinyl chloride copolymers II. Physicochemical, mechanical and thermal properties of the blends. Angew Makromol Chem 91:17-28. https://doi.org/10.1002/apmc.1980.050910102

16. Kozłowski M, Łaskawski W (1980) Wpływ wybranych kopolimerów chlorku winylu na właściwości poli (chlorku winylu). Przem Chem 59:87-90

17. Gadomska -Gajadhur A, Synoradzki L, Ruśkowski P (2018) Poly (lactic acid) for biomedical application-synthesis of biocompatible $\mathrm{Mg}$ catalyst and optimization of its use in polymerization of lactide with the aid of design of experiments. Org Process Res Dev 22:1167-1173. https://doi. org/10.1021/acs.oprd.8b00165

18. Vieira RP, Lona LMF (2016) Optimization of reaction conditions in functionalized polystyrene synthesis via ATRP by simulations and factorial design. Polym Bull 73:1795-1810. https://doi. org/10.1007/s00289-015-1577-z 
19. Mah KH, Yussof HW, Abu Seman NM, Mohammad AW (2019) Optimisation of interfacial polymerization factors in thin-film composite (TFC) polyester nanofiltration (NF) membrane for separation of xylose from glucose. Sep Purif Technol 209:211-222. https://doi.org/10.1016/j.seppu r.2018.07.041

20. Colonna S, Bernal MM, Gavoci G, Gomez J, Novara C, Saracco G, Fina A (2017) Effect of processing conditions on the thermal and electrical conductivity of poly (butylene terephthalate) nanocomposites prepared via ring-opening polymerization. Mater Des 119:124-132. https://doi. org/10.1016/j.matdes.2017.01.067

21. Chabbi A, Yallese MA, Meddour I, Nouioua M, Mabrouki T, Girardin F (2017) Predictive modeling and multi-response optimization of technological parameters in turning of Polyoxymethylene polymer (POM C) using RSM and desirability function. Measurement 95:99-115. https://doi. org/10.1016/j.measurement.2016.09.043

22. Chabbi A, Yallese MA, Nouioua M, Meddour I, Mabrouki T, Girardin F (2017) Modeling and optimization of turning process parameters during the cutting of polymer (POM C) based on RSM, ANN, and DF methods. Int J Adv Manuf Technol 91:2267-2290. https://doi.org/10.1007/s0017 0-016-9858-8

23. Ahmadipourroudposht M, Fallahiarezoudar E, Yusofa NM, Idris A (2015) Application of response surface methodology in optimization of electrospinning process to fabricate (ferrofluid/ polyvinyl alcohol) magnetic nanofibers. Mater Sci Eng C 50:234-241. https://doi.org/10.1016/j. msec.2015.02.008

24. Noordin MY, Venkatesh VC, Chan CL, Abdullah A (2001) Performance evaluation of cemented carbide tools in turning AISI 1010 steel. J Mater Process Technol 116:16-21. https://doi.org/10.1016/ S0924-

25. Cui W, Li X, Zhou S, Weng J (2007) Investigation on process parameters of electrospinning system through orthogonal experimental design. J Appl Polym Sci 103:3105-3112. https://doi.org/10.1002/ app. 25464

26. Nalimow WW, Czernowa NA (1967) Statystyczne metody planowania doświadczeń ekstremalnych. WNT, Warszawa

27. Draper NR, Guttman I (1992) Treating bias as variance for experimental design purposes. Ann Inst Statist Math 44:659-671. https://doi.org/10.1007/BF00053396

28. Achazarowa SŁ, Kafarow WW (1982) Optymalizacja eksperymentu w chemii i technologii chemicznej. WNT, Warszawa

29. Volk W (1973) Statystyka stosowana dla inżynierów. WNT, Warszawa

30. Stanisz A (2007) Przystępny kurs statystyki z zastosowanie STATISTICA PL na przykładach z medycyny Tom 2 Modele liniowe i nieliniowe. StatSoft, Kraków

31. Efroymson MA (1960) Multiple regression analysis. In: Ralston A, Wilf HS (eds) Mathematical methods for digital computers. Wiley, New York, pp 191-203

32. Koronacki J, Mielniczuk J (2006) Statystyka. WNT, Warszawa

33. Miller AJ (2002) Subset selection in regression 2nd edtion. Chapman and Hall, New York

34. Liebscher E (2012) A universal selection method in linear regression models. Open J Stat 2:153162. https://doi.org/10.4236/ojs.2012.22017

35. Breaux HJ (1967) On stepwise multiple linear regression. Report no. 1369. Ballistic Research Laboratories Aberdeen Proving Ground, Maryland

36. Chatterjee S, Hadi AS (2006) Regression analysis by example. Wiley, New Jersey

37. Draper NR, Guttman I, Kanemasu H (1971) The distribution of certain regression statistics. Biometrika 58:295-298. https://doi.org/10.1093/biomet/58.2.295

38. Agostinelli C (2002) Robust stepwise regression. J Appl Stat 29:825-840. https://doi. org/10.1080/02664760220136168

39. Rabiej M (2012) Statystyka z programem Statistica. Helion, Gliwice

40. Kukiełka L (2002) Podstawy badań inżynierskich. PWN, Warszawa

Publisher's Note Springer Nature remains neutral with regard to jurisdictional claims in published maps and institutional affiliations. 